\title{
Mecenas, impresores y artistas. Su papel en la edición de los libros en la segunda mitad del siglo XVI
}

\author{
Rosa Margarita Cacheda Barreiro *
}

\begin{abstract}
RESUMEN
ABSTRACT

Junto a los autores y mecenas, la

Together with the authors and the función principal del libro lo ocupa el papel del librero-editor de la obra. Tenemos que remontarnos al siglo xvi para entender que la figura del librero, editor y autor del libro responden, en

la mayor parte de los casos, a una misma persona. El grabador del Renacimiento se mantiene en el anonimato dejando - solo en muy escasas ocasiones-su huella a partir de las iniciales o del anagrama. patrons, the main role in the production of the book was placed by the publisher-bookseller of the work. We have to go back to the xvith century to understand that the figure of bookseller, publisher and author of the book were inited in one person. The Renaissance engravers remain anonymous, leaving -only in very few occasions - their mark through their initials or anagrams.
\end{abstract}

La estructura del libro ha ido evolucionando desde el incunable, sin datos tipográficos, hasta finales del siglo XVI. De esta forma se ha pasado del impreso del siglo Xv con la portada, dedicatoria, prólogo, láminas, poesía del autor, sumarios y colofón, a la incorporación, en la primera mitad del siglo XVI, del Privilegio, Licencias, Aprobaciones, con la inclusión, a partir de 1558, de la Tasa y Fe de erratas ${ }^{1 .}$

Universidad de Santiago de Compostela.

SIMON DIAZ, J.: El Libro español antiguo. Análisis de su estructura. Madrid, 1983, pág. 25.

Hay que tener en cuenta que los talleres españoles de las primeras décadas del siglo Xvi, continuaron con las caracteristicas que tenian en el siglo xv: el formato y el contenido de los libros 
El título de la obra, por lo general, es el inicio del frontispicio, escribiéndose en la parte superior, seguido por el autor con algunos de sus datos biográficos y académicos. La Corona obligó, en los siglos XV y XVI, de forma tajante, que el nombre del escritor figurase en la portada ${ }^{2}$. En este sentido nos encontramos que una gran mayoría de los autores de los libros forman parte de la jerarquía eclesiástica: obispos, (D. Juan Ruiz de Agüero, obispo de Zamora, D. Diego de Espinosa, obispo de Sigüenza, Stanislaus Hosius, obispo de Amberes, Melchor Cano, obispo de Canarias), arzobispos (D. Pedro Guerrero, arzobispo de Granada, D. Juan Martínez Silíceo, arzobispo de Toledo, D. Gaspar de Zúñiga, arzobispo de Santiago, D. Juan de Ribera, arzobispo de Valencia), cardenales (D. Gaspar Quiroga, cardenal y arzobispo de Toledo) presbíteros (D. Gaspar Cervantes de Gaete, presbitero cardenal de la Iglesia Romana y arzobispo de Tarragona) sacerdotes (D. Alonso Morgado, sacerdote de Alcántara), así como miembros de la orden franciscana ( $F$. Andrés Vega) dominica ( $F$. Francisco de Victoria, $F$. Domingo de Soto), agustina ( $F$. Alfonso de Orozco, F. Alfonso de Mendoza) y jesuita ( $F$. Juan Polanco, $F$. Juan Osorio, F. Francisco Arias) como grupo mayoritario, seguidos por los carmelitas ( $F$. Pedro de Padilla), cartujos ( $F$. Juan de Padilla) o mercedarios ( $F$. Juan Suárez de Godoy, F. Pedro de Oña) y cistercienses (Cipriano de Huerga) ${ }^{3}$. Profesores universitarios (Alfonso Garcia Matamoros, Pedro Serrano), teólogos (Miguel de Palacio), poetas (Juan Mena), humanistas (Benito Arias Montano), literatos, artistas (Juan de Arfe y Villafañe, Pedro Ángel) protagonizan, por otra parte, la autoría de estas obras.

Hay que romper con el tópico de que los escritores de los siglos XVI y xVII gozaron de la protección de los poderosos para quienes trabajaban o costearon la impresión de los libros que le dedicaban. Lo que sí es verdad es que los escritores intentaban acercarse a la Corte a través de adula-

eran similares. Los cambios que se fueron introduciendo fueron el fruto de una lenta evolución. obedeciendo a normas políticas, a necesidades sociales y mercantiles. Escolar SOBRINO. H.: Historia del libro español. Madrid, 1998, pág. 112.

EI Santo Oficio estimaba que la falta de cualquier dato esencial del autor era motivo suficiente para la prohibición total de la obra. Muchas veces se traducia el nombre civil del autor por un tílulo nobiliario o por un nombre retigioso si pertenecia a alguna orden. SIMON DiAz, J.: EI Libro Español Antıguo. Análisis de.... op. cit. págs. 3942.

A través de los libros. las órdenes religiosas desempeñan una función importante en la difusión y propaganda del culto a sus santos. surgiendo. por consiguiente, nuevos tipos iconográficos que ilustran gran parte de la portada, a modo de elemento identificador de la Orden. En este sentido, nos encontramos con grabados que recogen la estampa de San Francisco de Asis, Santo Domingo. San Jacinto o San Jerónimo escritos por los propios miembros de la orden en ese atán propagandístico. 
Mecenas, impresores y artistas. Su papel en la edición de los libros en la...

ciones y dedicatorias para agradar al interesado, como ocurre en gran parte de las portadas de estos libros ${ }^{4}$.

Dentro de la estructura de la portada y debajo del nombre del autor, se coloca - aunque no como un elemento obligatorio- el nombre de la persona a quien se dirige la obra. Simón Diaz establece una clasificación de los destinatarios del libro; en este sentido el primer grupo estaría formado por las figuras de Dios, Jesucristo, la Virgen y los santos. Un segundo grupo lo constituye los reyes, príncipes, nobles, magnates, la jerarquia eclesiástica y los superiores de las órdenes religiosas. Escritores, familiares y amigos forman el último de los grupos ${ }^{5}$. Las portadas de este apartado responden, en su totalidad al segundo tipo; hay que tener en cuenta que la actitud desinteresada y devota del primer y tercer grupo no puede ser habitual en una época en la que la edición de los libros estaba sometida al estricto control bajo el reinado de Felipe II. Desde este punto de vista es frecuente que los autores de libros busquen una seguridad en la figura del mecenas con un doble fin: la protección a posibles críticas y el pago de la edición. El monarca español como destinatario del libro, aparece en una gran parte de las obras de este trabajo por lo que la inclusión de los escudos imperiales en las portadas responde a esa actitud de reforzar la dedicatoria, quedando patente el importante papel desempeñado por la monarquía en la segunda mitad del siglo xvı y en concreto la figura de Felipe II en ese papel de mecenas y promotor de las artes y la cultura.

Junto a la monarquia, las altas jerarquías eclesiásticas constituyen el siguiente grupo importante de mecenazgo, siendo las figuras de los obispos y arzobispos las escogidas para las dedicatorias ${ }^{6}$. Escudos de armas de personajes como D. Pedro Guerrero, arzobispo de Granada, D. Diego de Espinosa, obispo de Sigüenza y otros muchos ilustran los frontispicios de estos libros.

Nobles, condes, duques, marqueses, constituyen el siguiente grupo importante en este papel de mecenazgo de la segunda mitad del siglo XVI, convirtiéndose en protectores de las artes, a la par que la monarquia, a

\footnotetext{
Simón Díaz, J.: "El Libro en Madrid durante el Siglo de Oro", en El Libro Antiguo Español. Actas del II Coloquio Internacional. Madrid, 1996, págs. 67-68.

Simón Diaz, J.: El Libro español antiguo.... op. cit., págs. 93-95.

Hay que tener en cuenta que el servicio episcopal no se refiere a la Iglesia en general, sino a las almas concretas de los fieles, por lo que las figuras del obispo y el arzobispo quedan revestidas, a partir de la Contrarreforma, de una nueva visión paternal y esposal como padre espiritual de los fieles y esposo de la Iglesia que le ha sido confiada, y desde esta óptica, debemos entender el papel de estos mecenas y la actitud devota del autor que confia "su obra" a la protección de la Iglesia. VV.AA.: Historia de la Iglesia en España de los siglos xV y XVI. 1980, pág. 163.
} 
quienes pretenden asemejarse, con un claro objetivo de ascenso económico y social ${ }^{7}$.

Junto a los autores y mecenas, la función principal en la producción del libro lo ocupa el papel del librero-editor de la obra. Tenemos que remontarnos al siglo XVI para entender que la figura del librero, editor y autor del libro que, actualmente desempeñan cargos muy distintos, en la época renacentista responden, de una forma mayoritaria, a una misma persona. En el siglo XVI son muchos libreros los que se dedican a la edición, adquiriendo de los autores sus obras, financiando su impresión y encargándose de la distribución y la venta. También algunos autores e instituciones ejercen de editores de obras financiando la producción ${ }^{8}$. Éste es el caso de personajes como Gabriel Lloberas, librero catalán, que imprime toda su obra, tal y como se refleja en algunas de las obras analizadas ("Addiciones a la Sylva Spiritual», de Antonio Álvarez, 1595) o Andrés Barrera, impresor y mercader de libros («Dilucidario y Demostracion de las Chronicas y Antigüedad del Sacro Orden de la Siempre Virgen Madre de Dios Sancta Maria del Monte Carmelo", de Diego de Coria Maldonado, 1598). Un tercer ejemplo sería la figura de Andrés Pescioni, impresor-librero, que se establece en Sevilla y de cuyo taller salen obras importadas tales como "Tractatus de Visitatione" (Baltasar Altamirano, 1581).

El librero editor ${ }^{9}$ no sale de su país y tampoco establece delegaciones en los principales centros comerciales del libro. Sin embargo, lograron poner a disposición de los lectores los libros españoles y extranjeros, pero se encerraron en su mercado interior, olvidando el importante papel de difusora de la cultura española ${ }^{10}$. Estos libreros españoles editan, por lo

El papel desempeñado por la nobleza sufre un cambio considerable a partir de la segunóa mitad del siglo XVI cuando es sustituido el carácter militar por las labores politico-administrativas, lo cual supuso un cambio radical en el concepto de la formación y virtudes del noble. A partir de ahora la educación del noble no será militar sino que se fundamentará en el estudio y conocimiento de las disciplinas humanísticas. De esta manera "las letras" se convertirán en un elemento caracteristico de la nobleza y de la monarquía y por ello protegerán las artes, actuando como mecenas de las obras del Renacimiento. MATILLA, J.M.: La Estampa en el Libro Barroco. Vitoria-Gasteiz, 1991, pág. 61.

La función básica en la producción del libro es la editorial. La industria gráfica, aunque de. sempeña un papel también importante en la producción material del libro, es dependiente de la primera. El libro refleja las exigencias del editor más que las posibilidades de calidad que pueda presentar el impresor. Moll RoOuETA. J.. «El impresor y el librero en el Siglo de Oro» en El Libro Antiguo Español... op. cit. pág. 32.

Suelen ser hombres de negocios y buscan obtener la máxima rentabilidad, un mercado que le asegurase un porvenir económico. Nava Rodriguez, M. "T.: La Educación en la Europa Moderna. Madrid, 1992, pág. 93.

10. La industria editorial española no desempeñó el espíritu empresarial que se necesitaba en ese momento. por lo que los editores de los principales centros europeos se aprovecharon de la si- 
general, obras en latín o en castellano; por el contrario no abordan ediciones completas castellanas de los grandes autores, actividad de la que se encargan los editores de los Paises Bajos. Esta caracteristica se refleja en los libros de este estudio que, en su mayoría responden a una temática religiosa de carácter devocional, siendo escasas las grandes obras compiladoras que necesitaban un mercado supranacional. Tampoco se abordan en la industria española las reediciones de autores clásicos latinos de difusión europea ${ }^{n}$.

En cuanto a la figura del impresor se caracteriza por ser una persona letrada, relacionada directamente con la cultura ${ }^{12}$, siendo muy habitual, en el mundo del Renacimiento, la relación existente entre el impresor y el humanista, como ocurre en el caso salmantino, en que la actividad editorial queda estrechamente vinculada a la Universidad ${ }^{13}$.

Por otra parte, la industria editorial española presenta un proceso evolutivo lento, en el que editor, impresor y librero trabajan al servicio de unos textos que pretenden difundir. La librería se convierte en el centro de difusión comercial de las ediciones, por lo que si el impresor quiere salir de la estrechez y dependencia en que habitualmente se encuentra, la mejor opción es incorporarse al mundo de la edición.

La producción libraria de la segunda mitad de siglo, se caracteriza, a la luz de los resultados obtenidos en este análisis, por una intensa actividad en los centros impresores de ciudades como Salamanca, Alcalá de Henares y Toledo. Le siguen Sevilla, Valladolid, Valencia, Madrid, Medina del Campo, Burgos, Barcelona, Zaragoza, Bilbao, Granada y Córdoba. La idea generalizada de que los impresores como hombres de negocios se asientan en aquellos lugares donde mejor pueda prosperar su negocio, buscando ciudades para dar salida a sus obras, no se cumple en el caso de Salamanca. Si los impresores y libreros acuden a esta ciudad es por su Universidad, contando con un número fijo de compradores entre los alumnos y profesores ${ }^{14}$.

tuación y ejercieron la actividad que le correspondía a los libreros-editores españoles. Se produce, por consiguiente, en este ambiente contrarreformista, de escaso contacto con el exterior, un gran desarrollo de las imprentas en manos de extranjeros. MOLL RoQuETA, J.: "El impresor y el librero..., op. cit. págs. 40-41. Fernandez Álvarez, F.: Felipe /ly su tiempo. Madrid, 1998, pág. 269.

1 Moll Roqueta, J.: "El libro español del...", op. cit., pág. 328.

12 Garcia VeGA, B.: El Grabado del Libro Español. Siglos XV-xVI-xvill. (Aportación a su estudio con los fondos de la Biblioteca de Valladolid). 1,ll. Valladolid. 1984, pág. 69.

is Checa CRemades, F.. "La imagen impresa en el Renacimiento y el Manierismo". en VV.AA: El Grabado en España (siglos xv al xvm). Summa Artis. XXXI. Madrid, 1990, pág. 193.

14 Ruiz Fidalgo. L.: La imprenta en Salamanca (1501-1600). Madrid. 1994, págs. 26-27. 
Dentro del grupo de impresores que trabajan en la ciudad salmantina a lo largo de esta segunda mitad de siglo destacan figuras como Alonso de Terranova, Andrés de Portonaris, Guillermo Foquel, Matías Gast, Pedro Madrigal, Juan Fernández o Juan Cánova.

Tanto Alcalá de Henares como Toledo, conservando su núcleo medieval, y como prolongación del mismo, se convertirán, a lo largo del siglo XVI, en dos grandes ciudades universitarias, contando con una variedad de producción tipográfica de un conjunto importante de talleres, por lo general, estables. En este contexto se enmarca la presencia de Antonio Sánchez Leyva, Andrés Angulo, Juan de Villanueva, Pedro de Robles, Juan Íñiguez de Lequerica, Francisco Cormellas, Fernando Ramírez, en las imprentas de Alcalá, siendo también numeroso el conjunto de impresores en los centros editoriales toledanos, entre los que destacan, Pedro Rodríguez, Alonso Gómez, Juan de la Plaza, Juan de Ayala, los hermanos Ferrer o Francisco y Tomás de Guzmán.

Entre los impresores que trabajan en la ciudad de Sevilla, figuran los nombres de Fernando Díaz, Alonso de Barrera o Andrea Pescione. Debemos resaltar, por otra parte, la labor tipográfica llevada a cabo en la ciudad de Valladolid por figuras como Francisco Fernández de Córdoba, Sebastián Martínez o Adrián Ghemart. En Valencia es la Familia Mey (Juan y Pedro Patricio) la protagonista de la actividad tipográfica de la ciudad levantina, a la que se añaden otros nombres como Pedro de Huete. En Madrid destacan los talleres de Luis Sánchez, Pedro Madrigal, Pedro de Mena o Guillermo Droy. Le siguen Francisco del Canto, en la imprenta de Medina del Campo, Felipe de Junta y Juan Bautista Varesio, en Burgos, Pedro Malo y Claudio Bornat, en Barcelona, Juan Soler y Domingo de Portonaris, en Zaragoza, Matías Mares, en Bilbao, Hugo de Mena, en Granada, siendo Gabriel Ramos y Andrés Barrera los nombres principales en la imprenta cordobesa.

Una última figura en la producción del libro es la del artista y grabador de las láminas, que se mantiene, por lo general, en el anonimato, dejando, sólo en muy escasas ocasiones, su huella a partir de las iniciales o del anagrama ${ }^{15}$. Hay que tener en cuenta que la función del grabado, a lo largo del siglo Xvi, era la de ilustrar del texto y no se valoraba el papel del autor o autores ${ }^{16}$. El grabador era considerado, en la mayoría de los

Los grabadores del siglo xvi, al igual que muchos de los impresores, fueron entalladores y plateros y tenian una formación inicial de orfebres y cinceladores, incorporándose con posterioridad al mundo del grabado. Portus, J; VEGA. J.: La Estampa Religiosa en la España del Antiguo Régimen. Madrid, 1998. pág. 22.

Garcia VEGA, B.: El Grabado en..., op. cit. pág. 83. 
Mecenas, impresores y artistas. Su papel en la edición de los libros en la...

casos, más artesano que artista, lo que se refleja en la poca creatividad de las láminas, siguiendo minuciosamente las directrices fijadas por el autor del libro ${ }^{17}$. Esta situación cambia a finales del siglo XVI, con la progresiva aparición de estampas en la que figura el retrato del autor, fruto del desarrollo individualista propio del Renacimiento y que alcanza su culminación en el grabado del mundo barroco ${ }^{18}$.

El grabado español del último tercio del siglo XVI y del siglo XVII y sobre todo la estampa de carácter religiosa, recibe la impronta de los maestros flamencos ya que su obra se difundió ampliamente por España a partir de catálogos que los propios grabadores importaban a nuestro país, así como a través de grandes obras como la Biblia Políglota de Amberes en donde la firma de los hermanos Wierix o de artistas como Pieter van der Heyden queda patente en varios de los grabados que ilustra la magna edición antuerpiense ${ }^{19}$.

Desde este punto de vista debemos subrayar que más de la mitad de la producción llevada a cabo en la segunda mitad del siglo XVI responde a ese espíritu conservador, religioso, que caracteriza el reinado de Felipe II y con él la mentalidad trentina, al que le siguen, con un índice de edición algo menor, las obras de carácter legislativo. Hay que tener en cuenta que un momento clave para la imprenta española se produce con la adquisición de los nuevos textos litúrgicos unificados con el Concilio de Trento ${ }^{20}$. Es a partir de este momento cuando la edición de Manuales de Predicadores, Sermonarios, como "Manuale chori secundu usum sanctae romanae ecclesiae" (1564) o "Summula per quam docta, resoluta, ac compendiosa de peccatis" (1571), "Piña de Rosas" (1589), Libros Sacramentales, Confesionarios: "Summa Sacramentorum Ecclesiae» (1572), Libros de formación religiosa: "Interogationes Clericorum" (1594), "Paradoxas christianas" (1592), "Catechismi duo et alia id genus pia opuscula» (1579), "Fratris Dominici Soto Segobiensis" (1577), "Concordancias de muchos passos difficiles de la Divina Historia" (1556), "Libri Decem hypotyposeon theologicarum" (1582), Tratados, Libros de oración, lecturas devotas (en

\footnotetext{
17 Matilla, J.: La Estampa en el libro..., op. cit., pág. 12

18 Checa Cremades, F.: "La imagen impresa en el Renacimiento...", op. cit., pág. 43.

19 DELEN, A.J.J.: Histoire de la gravure dans les Anciens Pays-Bas et dans les provinces belges des origines jusquia la fin du xv/ siecle. Paris, 1969, págs. 110-111.

20 Se crea, a partir de este momento, el Nuevo Rezado, que consiste en una operación de gran envergadura por la cantidad de ejemplares que fue preciso imprimir inicialmente en un plazo breve y que presenta una continuidad en el tiempo. MoLL ROQUETA, J.: «El impresor y el librero en el Siglo de Oro» en VV.AA.: El Libro Antiguo Español. Actas del II Coloquio Internacional. Madrid, 1992, pág. 37
} 
torno a la vida de Cristo, de María...), Hagiografías: "Meditaciones devotissimas del amor de Dios" (1597), "Francisci Sanctii Brocensis» (1587), "Rosario de Nuestra Señora" (1586), "La Hagiografía y vidas de los Sanctos de El Nuevo Testamento" (1580), Comentarios de los Evangelios, Libros sobre las Sagradas Escrituras: “Comentarios Escolásticos» (1584), "Conciones vespertinae Quadragesimales super septem poenitenciales psalmos" (1594), "Commentariorum loannis Feri in sacro sanctum lesu Christi evangelium secundum Matthaeum" (1562), "Gasparis Grajar sacrae theologiae" (1570), "de authoritate sacrae scripturae acea introductorum" (1585), misales, calendarios de la Iglesia romana, reglas de órdenes religiosas: "Breve directorium ad confesarii..." (1570), "Regulae societatis IESU" (1583), pedagogía y manuales de formación del cristiano (catecismos, disputaciones teológicas): "Aprovechamiento espiritual" (1593), "Luz del alma christiana" (1578), "De cultu adorationis" (1594), libros de oficios, fiestas, cánones y decretos sobre el Concilio de Trento: "Breve directorium ad confesarii..." (1570), concilios provinciales, historias sobre las diferentes iglesias españolas o constituciones sinodales del arzobispado. Esta teología moral y pastoral pretende, como fin último, fijar unos modelos de comportamiento abarcando la mayor parte de los aspectos de la vida humana; asimismo esta teología dogmática y científica servia para las lecciones escolares y universitarias ${ }^{21}$.

Es el Derecho la materia que sigue en número de ediciones en las obras analizadas en este artículo. Nos encontramos, por consiguiente, con recopilaciones de todas las pragmáticas de las cortes del reinado de Felipe II, así como constituciones pontificias o decretos canónicos. No es un hecho casual que una gran parte de las obras de esta temática hayan sido editadas en ciudades como Salamanca ya que es la legislación la materia que más fama dio a la universidad salmantina, así como sus autores (Domingo de Soto, Francisco de Vitoria) que elaboran sus escritos siguiendo la división clásica del derecho ${ }^{22}$. En este apartado se incluirían las siguientes obras: "Visita de la cárcel y de los presos" (1574), "Tractatus solemnis, utilis, quotidie practicabilis..." (1572), "Constitutionum Sanctissimorum patrum Summorumque Pontificum F.R: Pii IIII, Pii V, Liberunus" (1584), "Canones trium congregationum Generalium Societatis lesu “(1574).

Un tercer grupo estaria formado por la producción de obras de carácter histórico. La novedad más importante que ofrece la Historia durante el reinado de Felipe II es la aparición del sentido de investigación científica. Es así

Ruiz Fidalgo, L.: La Imprenta en Salamanca (1501-1600). Madrid, 1994, págs. $32-33$

Ruiz Fidalgo, L.: La Imprenta en salamanca..., op. cit., pág. 33. 
como nos encontramos con impresos que tratan sobre la Historia General de los reinos de España, hazañas y acontecimientos más destacados de la vida y política de determinados reyes, príncipes, nobles y grandes dignatarios: "Cinco Libros de la Historia de Portugal y conquista de las Islas Açores, en los años de 1582 y 1583", "Historiae de gentibus septentrionalibus", "Sumario de la Clarissima vida y heroycos hechos de los catholicos Reyes don Fernando y doña Ysabel, ..." (1574), «Fastos magistratum et Triumphorum Romanorum ab urbe condita ad augusti..." (1556).

Las obras de carácter filosófico constituyen otro de los grupos temáticos de este estudio. Es aquí donde se encuentran los libros que tratan el tema de la Lógica, considerada por los propios autores como la primera parte de la Filosofía, la Filosofía moral de príncipes para su buena crianza y gobierno: “Comentario a los tres libros del Alma de Aristóteles» (1579), "D. Francisci Toleti societatis iesu commentaria una cum quaestionibus in octo libros Aristotelis de Physica auscultatione" (1580). Las obras literarias -lírica y prosa ${ }^{23}$ - así como las de carácter filológico-lingüístico ocupan un espacio muy reducido dentro de la producción hispánica de esta segunda mitad de siglo. A su vez, durante este mismo periodo, se produce una fuerte influencia de los temas y formas de la Literatura clásica e italiana («Syntagma tragoediae Latinae», 1593).

A lo largo del siglo xvı se produce una recuperación consciente del pasado medieval y se editan algunas crónicas que hasta entonces permanecian manuscritas. Al mismo tiempo se inicia un proceso de decadencia de las novelas de caballerias que aludían a fantásticas hazañas de legendarios héroes que se habían recuperado en la literatura de la primera mitad, sustituyéndose, en la segunda mitad de la centuria, por la imagen de una visión antiheroica del mundo (Lazarillo de Tormes) ${ }^{24}$.

\footnotetext{
23 La lírica peninsular pasó por un momento decisivo con su incorporación a la vanguardia poética que provenia de Italia; se trataba de una poesía culta que reflejaba una nueva concepción del arte, del amor, la naturaleza. Sus modelos eran los cłásicos, sobre todo Petrarca y su origen filosófico Platón. La novela picaresca, con la aparición del Lazarillo de Tormes, la bizantina (aventuras amorosas en países lejanos) y la dramática son, entre otros, los géneros de nueva creación durante la época moderna. Dentro de este grupo se enmarcan obras en prosa, "Obras de Garcilasso de la Vega" (1580), en poesia, "loachimi Tydichii Berlinensis, poetae extemporaneorum carminum libri duo..." (1573), "Cancionero de López Maldonado" (1586), obras de teatro, "Propaladia de Bartolome de Torres y Naharro y Lazarillo de Tormes" (1586). VEGA GARCIA-LuENGOS, G.: "Las palabras perdurables: medio Siglo de Oro en la Literatura Española" en Felipe II, un monarca y su época. Conmemoración del IV Centenario de la muerte de Felipe II. Madrid, 1998, págs. $169-172$

24 En la primera mitad del siglo Xvi, los libros de caballerías alcanzaron un gran éxito - siendo uno de los géneros más abundantes durante el reinado de Carlos $V$ - por su idealismo amoroso y la exaltación del espiritu aventurero.
} 
Es durante el reinado de Felipe II cuando se produce un cambio en el interés de los temas de los libros impresos de acuerdo con el desarrollo cultural de la sociedad. Se produce un aumento en la edición de los libros científicos, así como un mayor conocimiento del cuerpo humano naciendo el estudio de la anatomía, con la creación de cátedras en las universidades de Salamanca, Valladolid y Valencia. Se produce, al mismo tiempo, un mayor conocimiento de la Tierra con la figura de España como una de las pioneras en los descubrimientos geográficos ${ }^{25}$. Destacan obras como "Tractado de alabança y murmuración..." (1572), "Dos libros, el ultimo que trata de las cosas que traen nuestras Indias Occidentales...” (1557), "Libro o práctíca de Cirugia» (1581), "Libro de enfermedades contagiosas y de la preservacion dellas" (1569), "De Morbo pustulato sive lenticulari» (1574). En el campo de las ciencias naturales, matemáticas y la Astronomia, hay que destacar obras como «Arismética, Practica, y especulativa del Bachiller Juan Perez de Moya" (1569).

El talante humanista de estas obras se observa en la edición de comedias, poemas, villancicos ilustrados con imágenes convencionales y de carácter popular. Es el caso de la "Sylva de varios romances", editado en Barcelona, en 1587. 